\title{
COMUNES FRENTE A LOS CERCAMIENTOS Y EXTRACTIVISMOS DE SOBREEXPLOTACIÓN \\ Una revisión desde el contexto de la pandemia del COVID-19
}

\author{
COMMONS IN THE FACE OF ENCLOSURES AND OVEREXPLOITATION \\ EXTRACTIVISMS \\ A review from the COVID-19 pandemic context
}

\author{
Laura Cecilia Razo Godínez*
}

\begin{abstract}
RESUMEN: La vuelta de los comunes ha sido la respuesta contrahegemónica más clara del siglo pasado frente al modelo neoliberal de cercamiento y extracción en los sures geográficos y políticos del mundo, específicamente en América Latina. Esto ha probado que los comunes no son solo un hecho existente en la realidad social rural y urbana, sino que, pueden ser vistos desde la óptica institucional $y$, sobre todo, como un proceso cultural cuyo alcance transformador viene a dar un nuevo valor a estructuras jurídicas y políticas. En el contexto de la pandemia, los comunes han demostrado ser necesarios para responder a las crisis colectivas que afrontamos. Son una resistencia fundamental que busca comunizar los derechos a través de la reapropiación de los espacios que permiten la reproducción de la vida.
\end{abstract}

\begin{abstract}
The return of the commons has been the clearest counter hegemonic answer of the past century against the model of enclosures and extractions in the geographic and political souths, specifically Latin America. This has proved that the commons are not just a current fact in rural and urban reality, but also, can be seen from an institutional point of view and moreover as a cultural process which has a transformative approach that adds new value to political and juridic structures. In the context of the pandemic, the commons have proved to be necessary to respond to the collective crises that we share. They are a fundamental resistance that looks for commoning the rights through the reappropriation of the spaces that allows the reproduction of life.
\end{abstract}

PALABRAS ClAVE: Comunes, Latinoamérica, neoliberalismo, cercamientos, extractivismos, pandemia, derechos humanos.

KEYWORDS: Commons, Latin America, neoliberalism, enclosures, extractivisms, pandemic, human rights.

Fecha de recepción: 23/02/2021

Fecha de aceptación: 23/02/2021

doi: https://doi.org/10.20318/universitas.2021.6205

* Doctoranda en el Instituto de Derechos Humanos Gregorio Peces-Barba de la
Universidad Carlos III de Madrid (UC3M), Master en Estudios Avanzados en Derechos
Humanos (IDHPB-UC3M), Especialista en Gestión de Políticas de Igualdad (IEG-UC3M),
Licenciada en Derecho por la Universidad Latina de México (ULM). Contacto:
lauraceciliarazo@gmail.com. 


\section{1.- INTRODUCCIÓN}

La pandemia del COVID-19 está siendo paradigmática respecto a los efectos globales que han traído consigo las políticas neoliberales, sobre todo para las personas históricamente más vulneradas. Paradójicamente, un virus que surge en el marco de una comunidad global ha dejado de manifiesto profundas desigualdades que imposibilitan a unos más que a otros la vida en un contexto tan complejo.

El presente artículo expone una serie de reflexiones abiertas y, por tanto, en constante actualización, que se han producido en el marco de la pandemia en torno a los comunes como respuesta ante las graves expansiones de los cercamientos y extractivismos de sobreexplotación, y cómo la implantación de estos han provocado un efecto diferenciado en las consecuencias que el COVID-19 ha tenido en distintos sectores poblacionales.

Para ello, se aborda de manera sucinta los acontecimientos que produjeron el giro neoliberal y la profunda conexión entre este y la desigual forma que ha afectado la pandemia, continuando con una aproximación del paradigma de los comunes como un relato creciente en América Latina, donde se viven con crudeza las injusticias que devienen del neoliberalismo.

De esta manera, se exponen los comunes que han gestionado necesidades básicas en el marco de la pandemia de COVID-19 resistiendo al proyecto extractivista y privatizador. Ante tales consideraciones, se finaliza con una serie de reflexiones entre comunes y derechos humanos que atiendan a realidades complejas como las de América Latina.

\section{2.- 50 AÑOS ANTES DE LA PANDEMIA DEL COVID-19.}

Medio siglo antes de la pandemia del COVID-19 se produjeron transformaciones profundas en las relaciones de los Estados con los mercados, de los mercados con la naturaleza y de los individuos con su medio natural y artificial, generando efectos globales, que, independientemente de ser o no responsables de los acontecimientos que han marcado el 2020, apuntan al menos a ser responsables de la precarización de las condiciones de vida de diversas latitudes del mundo, lo cual ha producido efectos diferenciados para algunas regiones y para algunos grupos poblacionales como es el caso de América Latina, en donde el COVID-19 ha producido efectos desiguales y en una mayor medida letal para algunas personas que para otras.

En la década de los setentas, la fuerza hegemónica de las élites económicas se vio amenazada por una crisis de sobreacumulación ${ }^{1}$ que

\footnotetext{
1 Para David Harvey, quien describe la composición operativa del capitalismo, las crisis de sobreacumulación son un destino recurrente del capitalismo, así como su antídoto, los aplazamientos temporales y/o espaciales de los cuales se hablará más adelante.
} 
generó movilizaciones sociales en distintos lugares del mundo levantadas por la inflación y el desempleo. Estas movilizaciones sugirieron una alternativa socialista que ponía en riesgo a las clases dominantes ${ }^{2}$. David Harvey considera que a esto se debió la creación del neoliberalismo como proyecto político de restauración del poder de las élites económicas, además, claro, de este proceso como un reacomodo para el restablecimiento de las nuevas condiciones para la acumulación del capital $^{3}$.

Dicho proceso involucró una nueva ola de cercamientos extractivistas, despojos y desarticulación de resistencias comunitarias, que, como ya lo han abordado en coincidencia autoras/es como Silvia Federici, Vandana Shiva, David Harvey, Peter Linebaugh, Pierre Dardot y Christian Laval o Mariarosa Dalla Costa, recuerdan mucho a los cercamientos ingleses del siglo $\mathrm{XV}$, en los que las autoridades feudales abolieron el sistema de acceso abierto y la gestión comunal de las tierras, prados, bosques y lagos, a través de los cuales se desarrollaba la autogestión colectiva y gratuita para la supervivencia de grandes masas de personas que no pertenecían a la burguesía. Así, con estos cercamientos, en palabras de Vandana Shiva, se «privó a los grupos políticamente más débiles de su derecho a la supervivencia y fue hurtando de la naturaleza su derecho a la autorrenovación y a la sostenibilidad al eliminar las limitaciones sociales al uso de los recursos» " ${ }^{\text {. }}$ En su momento, estos despojos, contrario al fin en base al cual se justificaban, es decir, una mejora en el manejo de los recursos, crearon una situación de pobreza generalizada, como lo pone en evidencia Silvia Federici cuando refiere que «un siglo después de tales cercamientos, setenta ciudades se vieron obligadas a instituir alguna forma de asistencia social y la indigencia se fue convirtiendo en un tema internacional» ${ }^{5}$.

Asimismo, desde la visión decolonial de teóricas/os como Silvia Cusicanqui, Ramón Grosfoguel, Aníbal Quijano y Alberto Acosta, existe una perspectiva compartida de que, para los países del sur, la imposición del capitalismo desde el inicio de la modernidad ha sometido a estos territorios a un cercamiento, extracción y explotación sin freno, privándoles continuamente de sus medios de subsistencia y su organización, generando condiciones de dependencia sistémica, a través de la cual, estos territorios se configuran como meros proveedores de bienes comunes, y sus pobladores en mano de obra precarizada y por tanto, explotada 6 .

\footnotetext{
${ }^{2}$ David Harvey, Breve historia del neoliberalismo (Editorial Akal, 2007) 20.

3 ibíd., 23.

${ }^{4}$ Vandana Shiva, Manifiesto por una democracia de la tierra, justicia, sostenibilidad y paz (Paidós Ibérica, 2006) 40.

${ }^{5}$ Silvia Federici, Calibán y la Bruja, Mujeres, cuerpo y acumulación originaria (Traficantes de Sueños, Madrid, 2015) 33.

${ }^{6}$ Grosfoguel propone que las prácticas extractivas no tienen nada de nuevas y cita a Acosta: "El extractivismo es una modalidad de acumulación que comenzó a fraguarse masivamente hace 500 años con la conquista y la colonización de América, África y Asia
} 
Para Harvey, este reiterado surgimiento del violento proceso de acumulación primitiva, se debe a que el capitalismo tiene la tendencia a producir sobreacumulación, los excedentes de capital y de fuerza trabajo son cubiertos mediante desplazamientos temporales y/o desplazamientos espaciales que se traducen en una continua expansión y producción del espacio para el capital7. En este sentido, el referido autor argumenta que el proceso de acumulación primitiva no puede ser considerado como un hecho único fundante, sino una condición del proceso de acumulación capitalista y, por tanto, un hecho en curso, sustituyendo el concepto de acumulación primitiva por el de acumulación por desposesión ${ }^{8}$. Rosa Luxemburgo anticipaba que esto se debe a que «el capitalismo requiere de la constante subordinación de regiones o grupos sociales que le son exteriores para su continuado crecimiento y permanencia» ${ }^{9}$. De tal suerte que el capitalismo neoliberal vendría a ser un nuevo proceso de desposesión así como de expansión.

Como consecuencia de este modelo de explotación y consumo que se ha venido consolidando las últimas décadas. El resurgimiento de los comunes responde en rebeldía y bajo condiciones de necesidad a los valores centrales del proyecto capitalista neoliberal, mostrando antes y durante la pandemia, como lo establecen Negri y Hart, que las organizaciones políticas alternativas se construyen dentro del propio imperio ${ }^{10}$.

\section{3.-NUEVOS CERCAMIENTOS Y EXTRACTIVISMOS DE SOBREEXPLOTACIÓN EN AMÉRICA LATINA}

Bajo las consideraciones anteriores, la globalización capitalista que inauguró un nuevo orden mundial, dio inicio a través de ambiciosos

empezó a estructurarse la economía mundial: el sistema capitalista. Esta modalidad de acumulación extractivista estuvo determinada desde entonces por las demandas de los centros metropolitanos del capitalismo naciente. Unas regiones fueron especializadas en la extracción y producción de materias primas, es decir, de bienes primarios, mientras que otras asumieron el papel de productoras de manufacturas. Las primeras exportan naturaleza y las segundas la importan." Ramón Grosfoguel, "Del extractivismo económico al extractivismo epistémico y al extractivismo ontológico: una forma destructiva de conocer, ser y estar en el mundo" (enero-junio 2016) Tabula Rasa, Bogotá Colombia, No. 24, 35.

<https://revistas.usc.gal/index.php/ricd/article/view/3295> última consulta: $15 / 02 / 2021$.

7 David Harvey, "El nuevo imperialismo: Acumulación por desposesión" (2005) CLACSO, Buenos Aires, Argentina, 100-101.

$<$ https://ticsymovimientos.files.wordpress.com/2017/03/harvey-acumulacic3b3n-pordesposesic3b3n.pdf> última consulta: 15/02/2021.

${ }^{8}$ David Harvey, El nuevo imperialismo. Acumulación por desposesión (CLACSO, Buenos Aires, 2005) 113.

${ }^{9}$ Rosa Luxemburgo, La acumulación del capital, (Cenit, Madrid, 1933)116-117.

${ }^{10}$ Michael Hardt, Antonio Negri, Imperio (1a edición, Paidós, 2005). 
proyectos de cercamientos extractivistas ${ }^{11}$ que consistieron como en otros tiempos, en despojos, privatizaciones y proyectos de sobreexplotación. Estos procesos de acumulación fueron instalados, sobre todo, en los sures geográficos y políticos del mundo y vendrían a eliminar el control comunal de los medios de subsistencia y la capacidad de las personas de cubrir sus propias necesidades, una afrenta directa a la reproducción ${ }^{12}$. Este pillaje a gran escala fue impulsado a través de los conocidos Programas de Ajuste Estructural forzados en los sures a través del uso de la fuerza militar y financiera recreando la condición de sin tierra como hace cinco siglos. María Rosa Dalla Costa lo rememora de forma atinada:

\begin{abstract}
"Si es indudablemente verdadero que aquellos años en Italia fueron de represión y de normalización, en el tercer mundo fueron los años del ajuste drástico dictado a los distintos gobiernos por el Fondo Monetario Internacional. El ajuste ha concernido a casi todos los países y luego también al nuestro, pero sus modalidades en el tercer mundo contemplan medidas no válidas para nosotros. Por ejemplo, el retiro de subvenciones para los bienes alimenticios de primera necesidad y sobre todo la fuerte recomendación del Fondo a los gobiernos de fijar un precio a la tierra, de privatizarla en donde constituye todavía un bien común (como fuera para un amplio sector de África) imposibilitando con esto la agricultura para el consumo. Esta medida (...) constituye según mi opinión, la primera causa de hambre en el mundo y de la producción de una población que aparece cada vez más sobreabundante porque vuelve a la condición de "sin tierra" como hace cinco siglos"13
\end{abstract}

Para la referida autora, estos programas de ajuste de los años ochenta representaron una operación de subdesarrollo de la reproducción a nivel global, al rebajar las condiciones de vida de las poblaciones y provocar una pobreza sin precedente ${ }^{14}$. Como se ha abordado anteriormente, este proceso se ha implementado de forma desmedida en América Latina. Un ejemplo paradigmático de ello ha sido el Tratado de Libre Comercio de América del Norte (TLCAN) en 1990, a través del cual, atendiendo a estas presiones, fueron implantadas una serie de reformas en el marco jurídico interno en México, que permitieron la mercantilización, privatización y explotación de bienes comunes aboliendo la tenencia comunal de la tierra, obra de la constitución social de 1917, produciendo no solo un empobrecimiento de las capacidades de gestión y

\footnotetext{
${ }^{11}$ A lo largo del presente artículo se hablará de cercamientos extractivistas para hacer referencia a todos aquellos procesos privatizadores que han demandado extracciones de sobreexplotación.

12 El término reproducción, mayormente aceptado y estudiado desde la década de los setentas a través de los estudios feministas, hace referencia, según Silvia Federici, al complejo de actividades y relaciones gracias a las cuales nuestra vida y nuestra capacidad laboral se reconstituyen a diario. Silvia Federici, Revolución en punto 0 , Trabajo Doméstico, Reproducción y Luchas Feministas (Traficantes de Sueños, Madrid, 2013) 21.

${ }^{13}$ Mariarosa Dalla Costa, "La puerta del huerto y del jardín" (2005) Nóesis, Revista de Ciencias Sociales y Humanidades, 94.

14 ibíd.
} 
la sostenibilidad de los bienes, sino, además, una reprimarización de economías como la mexicana, convirtiéndola en un mero origen de bienes comunes. Trayendo consigo una afectación directa en la vida de las personas lo bastante profunda como para convertir en migrantes a poblaciones enteras ${ }^{15}$.

Otro ejemplo claro que ello ha sido la Revolución Verde, un cercamiento extractivista que ha ido suplantando la agricultura de subsistencia por la agricultura industrial ${ }^{16}$ no como resultado de una paulatina y natural industrialización del campo, sino como la imposición vertical por fuerzas externas en el marco de una crisis de sobreacumulación. Esa transformación de la reproducción social ha privado al campesinado, agricultoras/es y poblaciones indígenas de la posibilidad de reproducir su vida de manera autónoma. Las mujeres han sido las más vulneradas, sufriendo una reestratificación que las ha condenado a estar más explotadas y empobrecidas.

En el contexto latinoamericano, lo anterior no se puede explicar únicamente a través de las presiones de organismos internacionales o los tratados internacionales que fomentan estos sistemas de dependencia sistémica, sin la importante implicación que han tenido los Estados en estos procesos, ya que en las últimas décadas han pasado de una posición permisiva a una notoriamente involucrada, dedicándose incluso a fomentar el marco jurídico idóneo como si fuera la solución a la precariedad en la que se vive.

Se crea, además, una suerte de competencia entre Estados por atraer y acaparar estos capitales ${ }^{17}$. Para Ferrajoli, esto es sintomático de la inversión clara de la relación entre la política y la economía ${ }^{18}$.

Como ya se mencionaba anteriormente, en cada época de cercamientos, estos controles sobre la reproducción social han tenido implicaciones en las relaciones sociales, la relación con la naturaleza y con las prácticas y bienes que permiten la reproducción de sociedades enteras, en la transformación de lo común en relaciones de propiedad norte-sur.

\footnotetext{
${ }^{15}$ Ver más en "La agricultura y su relación con la pobreza en México" CEDRSSA, (2020) <http://www.cedrssa.gob.mx/files/b/13/17Agricultura pobreza.pdf > última consulta: 15/02/2021.

${ }^{16}$ Vandana Shiva explica:

"Durante la Segunda Guerra Mundial las grandes empresas amasaron enormes cantidades de dinero con la muerte de millones de personas. Cuando acabaron las guerras una industria que había crecido y cosechado grandes beneficios fabricando explosivos y productos químicos para la contienda y para los campos de concentración se reinventó y resurgió como industria agroquímica. Como se enfrentaban al cierre $o$ al cambio de actividad, las fábricas de explosivos empezaron a producir fertilizantes sintéticos, y los químicos de guerra comenzaron a emplearse como pesticidas $y$ herbicidas. En el núcleo de la agricultura industrial se encuentra el empleo de venenos" Vandana Shiva, ¿Quién alimenta realmente al mundo? (Capitán Swing Libros, 2018) 35.

${ }^{17}$ Eduardo Gudynas ha dedicado su obra a analizar estos fenómenos en América Latina.

${ }^{18}$ Luigi Ferrajoli, Manifiesto por la Igualdad (Editorial Trotta, Madrid, 2019) 81-85.
} 
Lo que hace de estos nuevos cercamientos y extractivismos de sobreexplotacion un problema como ningún otro, es, por un lado, la cada vez más pronunciada brecha entre quienes se enriquecen de estos emprendimientos y quienes sufren las consecuencias de su proliferación, el proceso de precarización que este proceso conlleva y las irreversibles consecuencias por la sobreexplotacion de la naturaleza.

Como consecuencia de estos procesos, tal y como han venido reiterando instituciones como la Comisión Intergubernamental sobre Cambio Climático, mejor conocida como IPCC ${ }^{19}$, el ser humano ha provocado un grave desequilibrio en la naturaleza, al grado de que el capital se ha convertido en depredador del espacio en el que se reproduce. Como se puede desprender de una nota de Suzzane Goldberg en The Guardian, para 2013, sólo 90 empresas eran responsables de dos tercios de las emisiones de efecto invernadero. De entre las cuales, 50 eran privadas, 31 públicas y 9 Estados-Nación ${ }^{20}$. De ahí, que los desequilibrios ecológicos han sido mayormente producidos por emprendimientos extractivos y a estas actividades oligopólicas se debe, ya no solo el calentamiento global, sino, además, las próximas enfermedades virales para los seres humanos ${ }^{21}$. A este respecto, los epidemiólogos Fauci y Morens han coincidido en anunciar que la propia pandemia del COVID-19 inauguró una era de pandemias que será provocada por el complejo y cambiante escenario global ${ }^{22}$.

El modelo de desarrollo extractivo y privatizador que se ha impulsado como parte de la agenda neoliberal pone de manifiesto la afrenta contra la reproducción, así como la vinculación de estos con la actual precariedad global.

Bajo este marco económico, social, político y ecológico, no es ninguna coincidencia que se hayan generado diversas organizaciones populares de subsistencia. La vuelta de los comunes, a la que hace alusión Peter Linebaugh ${ }^{23}$ simplifica, de cierto modo, este proceso de transformación social que se viene gestando como consecuencia de la agenda de cercamientos extractivistas que han marcado la segunda mitad del siglo pasado. Las resistencias comunes han terminado por convertirse

\footnotetext{
${ }^{19}$ Cabe mencionar, tal y como lo comenta Jorge Riechmann, que este organismo no exagera a este respecto, sino que, de hecho, aún a pesar de lo que ha pronunciado en sus informes, ha estado infraestimando sistemáticamente el Cambio Climático. Jorge Riechmann "El síntoma se llama calentamiento climático pero la enfermedad se llama capitalismo" (2014) web viento sur, 1-69, Recuperado de:

<https://www.elviejotopo.com/wp-content/uploads/2016/01/Texto Riechmann.pdf> última fecha de consulta: 15/02/2021.

20 ibíd., 17.

21 Morens David M, Fauci Anthony S, "Emerging Pandemic Diseases: How We Got to COVID-19" (2020) Cell Press, 1077.

<https://www.cell.com/action/showPdf?pii=S0092-8674\%2820\%2931012-6> última

fecha de consulta: 15/02/2021.

22 ibíd., 1086.

${ }^{23}$ Peter Linebaugh, Stop the Thief! The Commons, Enclosures and Resistance, (Spectre, 2014).
} 
en algo más que una organización alterna para cubrir necesidades básicas ya que, en última instancia, han mostrado reconstruir el tejido social, restaurar el sentido de comunidad y fomentar la participación ciudadana, convirtiendo en central y decisivo el involucramiento de mujeres, tal y como se ha podido analizar a través de experiencias como las ollas comunes, los huertos urbanos, las madres comunitarias, las viviendas comunes, los bancos de tiempo, entre muchos otros proyectos.

El retorno de los comunes representa, pues, una de las luchas contrahegemónicas más clara de los últimos tiempos ya que pone en entredicho el proyecto neoliberal que, como se verá más adelante, se ha justificado como una solución al trágico destino de los comunes.

\section{4.- EL RETORNO DE LOS COMUNES: EL RELATO DE UNA CARTOGRAFÍA CRECIENTE}

"Nuestra tarea política, argumentamos, no es, simplemente, resistir a estos procesos, sino reorganizarlos y redirigirlos hacia nuevos fines. Las fuerzas creativas de la multitud que sostienen al Imperio son también capaces de construir un contra- Imperio, una organización política alternativa de los flujos e intercambios globales. Las luchas para contestar y subvertir al Imperio, como asimismo aquellas para construir una alternativa real, tendrán lugar en el mismo terreno imperial - y desde luego esas luchas ya han comenzado a emerger. Por medio de esas luchas y muchas más como ellas, la multitud deberá inventar nuevas formas democráticas y un nuevo poder constituyente que habrá de llevarnos algún día a través y más allá del Imperio."24

El panorama de lucha y resistencia de los movimientos altermundistas de finales de los $80 \mathrm{~s}$ y principios de los $90 \mathrm{~s}$ por la reapropiación de los espacios de reproducción de la vida, dan cuenta del malestar social vivido ante la implantación de mecanismos de despojo. Bajo ese contexto se desarrollaron las investigaciones de Elinor Ostrom ${ }^{25}$, inaugurando una serie de estudios que lograron desmitificar, a través de experiencias empíricas de comunidades autogestivas, la naturalidad con la que se aceptó la tragedia de los comunes ${ }^{26}$, que, de forma muy breve, fue una de las publicaciones más influyentes en el tránsito al neoliberalismo, y por la cual, se consideró a los proyectos autogestivos como una amenaza para la productividad y una buena gestión de los recursos, advirtiendo, como los únicos escenarios posibles para una gestión efectiva, la gestión privada y la gestión estatal.

Esta aseveración prevenida por Garret Hardin, establece que los bienes comunes estuvieron sujetos a una tragedia sobrevenida por el egoísmo que caracteriza a los individuos racionales y concluyó que estos

\footnotetext{
24 Michael Hart, Imperio, 7.

${ }^{25}$ En 2009, Governing the commons o El Gobierno de los Comunes en castellano, le valió a la referida autora el Premio Nobel de Economía.

${ }^{26}$ Garret Hardin, "La tragedia de los comunes" (2004) CULCYT: Cultura Científica y

Tecnológica, Vol.1, N³, 2.

$<$ https://dialnet.unirioja.es/servlet/articulo?codigo $=7270922>$ última consulta: $15 / 02 / 2021$.
} 
bienes están destinados a una suerte trágica ya que cada individuo siempre busca un interés personal, explicándolo a través de la metáfora de la pastura ${ }^{27}$. Bajo esta premisa, los cercamientos extractivistas se han justificado como una solución a este destino trágico de los comunes.

La contribución de Ostrom fue respaldar empíricamente su teoría de la acción colectiva autoorganizada, visibilizando los comunes como un paradigma que es igual de posible que el estatal y el privado. Introdujo una base teórica para contrarrestar los derechos de propiedad como derechos absolutos y de exclusión cuestionando los cercamientos como tratamientos que fomentan una dependencia sistémica, así como el agotamiento de estos bienes, además de desechar la premisa de que los individuos son incapaces de cambiar las reglas que les afectan y por ello requieren ser organizados por autoridades externas, dígase el Estado o los entes privados ${ }^{28}$.

A pesar de las críticas que teóricos como Bollier, Dardot, Laval o Harvey sostienen con respecto a la institucionalización de los comunes a la que refiere Ostrom, tal y como lo menciona Luis Lloredo en su artículo Bienes Comunes, la consideración de Ostrom de que la gestión eficaz no se produce por la homogeneidad de una comunidad dada, sino por los diseños institucionales en el marco de una comunidad que puede ser heterogénea, es un punto de partida no sólo valioso sino necesario para repensar alternativas de gestión y participación en contextos complejos y diversos 29 .

Ahora bien, este nuevo paradigma ha propiciado la implementación de conceptos muy variados que se han utilizado para contrarrestar la lógica de los proyectos neoliberales de despojo, incluyendo acepciones tales como comunes, lo común, bien común, bienes comunes, commoning y procomún ${ }^{30}$.

En lo que hace a este artículo, se ha elegido hablar de comunes desde una perspectiva que concibe estos como el producto de una serie de actos de commoning construidos a través de redes, prácticas y vínculos de coactividad, sin que para ello sea necesaria la existencia de

${ }^{27}$ En esta metáfora, cada pastor agrega ovejas en un pastizal de acceso abierto. Cada pastor recibe los beneficios de agregar ovejas y, el costo por la degradación, es compartido entre los pastores. Como se desprende, a cada pastor le conviene agregar ovejas sin límites, pero los recursos son finitos lo que conlleva a la sobreexplotación. Se produce un dilema irracional en los pastores racionales. ibíd.

${ }^{28}$ Elinor Ostrom, El gobierno de los bienes comunes (Fondo de Cultura Económica, DF, México, 2000) 56, 290.

<https://www.crim.unam.mx/web/sites/default/files/El\%20gobierno\%20de\%20los\%20b ienes\%20comunes.pdf> última consulta: 15/02/2021.

${ }^{29}$ Luis Lloredo, "Bienes Comunes" (2020) Eunomía, Revista en Cultura de la Legalidad, 19, 219.<https://e-revistas.uc3m.es/index.php/EUNOM/article/view/5709>

última consulta: 15/02/2021.

${ }^{30}$ Para una explicación detallada de estos conceptos, su diferenciación y clasificación ver: Lloredo Alix "Bienes comunes" (2020) Eunomía, Revista en Cultura de la Legalidad, 19. <https://e-revistas.uc3m.es/index.php/EUNOM/article/view/5709> última consulta: $15 / 02 / 2021$. 
una comunidad previa. Esta concepción deviene además de lo común como principio político ${ }^{31}$ tal y como lo conciben Dardot y Laval. Es decir, los comunes como resultado de procesos que requieren de un sentido de responsabilidad política en la creación y mantenimiento de espacios de la reproducción de la vida.

Desde este lenguaje de los comunes se buscan abordar las tensiones entre los comunes y el capitalismo neoliberal; confrontar las políticas de cercamiento extractivista sobre la base de los principios de libre acceso, uso común y la autogestión, proponer el análisis de modelos sociales que han logrado reconstruir el tejido social y el sentido de comunidad, reparando los daños que la lógica capitalista ha producido.

Antes de la pandemia de 2020, el incremento y expansión de organizaciones populares solidarias dieron cuenta de las condiciones que imponía el sistema económico, político y social actual, de cómo ello afecta severamente a las poblaciones, surgiendo problemas vitales como el hambre, la falta de agua, vivienda, educación y cuidados. Con lo cual, fue posible presenciar proyectos en el ámbito rural, urbano y digital, autoorganizados, con una alta participación de mujeres y de base asamblearia.

\section{5.- COMUNES EN LA PANDEMIA DEL COVID-19}

En el marco de la pandemia, cuando la fragilidad de los cuerpos ha demandado su resguardo, ha quedado al desnudo la amenaza que representa para la supervivencia de grandes sectores poblacionales el quedarse en casa, más aún que el hecho de salir de ella, cuando no todas y todos tienen garantizadas las necesidades básicas para la supervivencia en condiciones de encierro o, incluso, cuando existe la imposibilidad del cumplimiento del requisito básico de lavarse las manos, debido a que en plena pandemia existen comunidades enteras sin acceso a un bien vital como el agua. A este respecto, David Harvey, en un ensayo realizado en el transcurso de la pandemia, recuerda que, tras el temblor de 1985 en la Ciudad de México, se descubrió la situación precaria en la que trabajaba el gremio de las costureras, llamándolo temblor de clase y sugiriendo que en la actual pandemia, al igual que en aquel temblor, el mundo se encuentra presenciando una pandemia de clase, género y raza ${ }^{32}$. Donde poco tiene que ver con la circunstancialidad y mucho, con las desigualdades estructurales naturalizadas.

En este sentido, la crisis que ha representado la pandemia de COVID-19, ha sido un catalizador para el aumento de la cartografía de los comunes. Clarisa Hardy, da cuenta en la reedición de su libro Dignidad + Hambre = Ollas Comunes, de la reaparición en Chile de las ollas comunes a pocos meses del inicio de la pandemia del COVID-19, como un fantasma

${ }^{31}$ Christian Laval y Pierre Dardot, Común, (Editorial Gedisa S.A, Madrid, 2015)

32 Agamben, Giorgio, Slavoj Zizek, Sopa de Wuhan (Aislamiento social preventivo y obligatorio, marzo 2020) 93. 
del pasado ${ }^{33}$. Desde el Observatorio de Género y Equidad, Hillary Hiner advierte del resurgimiento de organizaciones de mujeres populares, que, ante el desamparo del Estado, se han organizado entorno a redes territoriales de subsistencia como una suerte de la extensión de los cuidados femeninos desde el hogar a la comunidad ${ }^{34}$. En el sur de Lima, han aparecido colectivos de mujeres como Manos a la Olla ${ }^{35}$ para atender la necesidad de alimentación a través de campañas como Cuarentena Digna. En Bolivia estas ollas son cocinadas y servidas en las calles de los barrios más empobrecidos alimentando a niñas y niños, jóvenes y ancianas/os.

La cantidad de huertos urbanos que se han ido aperturando desde Buenos Aires hasta la Ciudad de México, dan cuenta de la necesidad de resolver problemas como el hambre en las ciudades y la educación ambiental que es necesario implementar en estos espacios urbanos. En Colombia, las Madres Comunitarias han iniciado sus propios huertos, introduciendo, además, dentro de las enseñanzas a las niñas y niños, estos espacios como sistemas de producción de alimentos, una herramienta contra la carencia de alimentos y la necesaria vinculación de los humanos con la naturaleza.

No hay mejor evidencia de la expansión de la precariedad y la pobreza que el surgimiento de estas organizaciones comunitarias solidarias que cubren las necesidades vitales que los Estados no han podido garantizar. En la pandemia del COVID-19 estas carencias son un indicador de un necesario replanteamiento de los derechos humanos.

Así, los comunes que, como ya se ha venido mostrando, han aparecido como resistencia desde antes de la pandemia y, en medio de esta, emergen para evitar la muerte, el hambre y la explotación. El incremento de las resistencias ha sido tal, que más que resistencias aisladas, lo que se plantea, es que los comunes son un hecho creciente en la realidad rural y urbana, una cartografía en crecimiento y quizá, en breve, no solo hechos y estrategias institucionales, sino un nuevo proyecto político y social que vendrá a irradiar estructuras jurídicas y políticas para poder garantizar la reproducción de la vida.

En este sentido, esta cartografía creciente en todas las latitudes de Latinoamérica, muestra una reapropiación y democratización de los espacios y a una ciudadanía activa, creativa y participativa cuyos desafíos son la comunalización de todos los procesos vitales que permitan la vida de la mayoría. Los comunes como commoning podrían ser considerados como una serie de hechos configuradores de un proceso de transformación, que incluso incita al replanteamiento de los derechos

${ }^{33}$ Clarisa Hardy, "Dignidad + Hambre = Ollas Comunes" (LOM ediciones, Agosto 2020) 10.<https://eurosocial.eu/wp-content/uploads/2020/10/Hambredignidad web.pdf > última consulta: 15/02/2021.

34 Hillary Hiner "Las raíces históricas de las ollas comunes" (Observatorio de Género y Equidad) <http://oge.cl/las-raices-historicas-de-las-ollas-comunes/> última consulta: $15 / 02 / 2021$.

${ }^{35}$ Ver más vía twitter en: @manos_olla 
como el único lenguaje a través del cual es posible atender las crisis actuales.

De tal modo que, los comunes son un nuevo paradigma para la filosofía política y la filosofía de los derechos fundamentales y vienen a cuestionar si los derechos y las estructuras políticas y jurídicas que los pretenden garantizar son suficientes en un contexto cada vez más complejo.

\section{6.- COMUNES: UN NUEVO PARADIGMA PARA LOS DERECHOS HUMANOS. REFLEXIONES EN MEDIO DE LA PANDEMIA}

En consecuencia con lo visto a lo largo de este artículo, resulta necesario comenzar con la discusión como la que propone Ferrajoli con respecto a la constitucionalización de los bienes comunes como una de las opciones para evitar su explotación, pero ¿Es suficiente? ¿Sería necesario plantear además una postura crítica a la constitucionalización de estos y a lo que algunos autores consideran como una domesticación de los comunes? Si bien, este concepto pone en marcha una nueva valoración sobre los derechos fundamentales y un necesario replanteamiento de alternativas jurídicas que permitan garantizar no solo derechos sino un catálogo de bienes, ¿Esto realmente garantiza que en panoramas convulsos pueda frenarse, al punto de ser significativo, la destrucción producida por los proyectos desarrollistas?

Aun así, el constitucionalismo de los bienes comunes plantea una estrategia real y plausible que puede permitir contar con mayores herramientas que limiten la expansión del capitalismo a espacios vitales. En este sentido, ¿La constitucionalización de los bienes podría ser una medida de tránsito en tanto la cartografía de los comunes sigue tejiendo redes y vínculos dando lecciones a las estructuras tradicionales al asumir los derechos desde una visión integral, considerando la interdependencia global, intergeneracional y la eco-dependencia?

\section{7.- REFLEXIONES FINALES}

La pandemia del COVID-19 está siendo un momento histórico paradigmático que provoca necesarias reflexiones en torno a cuestiones centrales relacionadas con los derechos. Si bien, desde antes de la pandemia las consecuencias que el giro neoliberalizador había traído para América Latina eran notorias en lo que hace al ataque a la reproducción de poblaciones enteras y la brecha cada vez más grande de desigualdad, no ha sido sino hasta este momento que se ha desvelado con crudeza cómo como el virus tiene efectos diferenciados donde la población parte de una desprotección absoluta por ser lugares que permanentemente han permanecido explotados y donde el acceso a derechos es mayormente desconocido. 
La reflexión en torno a los comunes a partir de este evento histórico ha resaltado cómo estos surgen en escenarios de una vulnerabilidad absoluta para cubrir necesidades básicas como la alimentación y los cuidados. Tal y como se pudo observar, en el año 2020 se hicieron visibles una cantidad considerable de proyectos autogestivos generados para cubrir estas necesidades, haciendo visible, no por coincidencia, que los comunes proliferan en contextos como el latinoamericano para garantizar la supervivencia y son mayormente gestados por mujeres 0 que existe, al menos, una alta participación femenina.

Finalmente, el hablar de los comunes conlleva a problematizar el discurso de los derechos humanos con el objetivo de visibilizar lo corto que se queda el discurso para poblaciones enteras y la falta que hay de alternativas que permitan integrar realidades que acepten la vulnerabilidad como presupuesto de los seres humanos. Este periodo coyuntural, desde la óptica de los comunes y los derechos, también requiere un necesario reconocimiento de los primeros como un hecho en la realidad actual y finalmente, de su reconocimiento como un proceso transformador que viene a atravesar el ámbito social, económico y político, forzando la reflexión de estructuras jurídicas como los derechos desde una visión relacional que el momento presente nos exige analizar.

\section{6.- BIBLIOGRAFÍA}

\section{1.- Libros}

Agamben G y Zizek S, Sopa de Wuhan, (Aislamiento social preventivo y obligatorio, marzo 2020)

Dalla Costa M, Perlas y Flores en la reproducción feminista (Akal, Madrid, 2009)

De Lucas J, El concepto de solidaridad (Primera edición, Distribuciones Fontanara S.A, México, 1993)

De Sousa Santos B y Meneses M, Epistemologías del Sur (Akal, España, 2014)

Escobar Arturo, La invención del tercer mundo, construcción y deconstrucción del tercer mundo (Primera edición, Fundación Editorial el perro y la rana Caracas, Venezuela, 2007)

Federici S, Calibán y la Bruja, Mujeres, cuerpo y acumulación originaria (Traficantes de Sueños, Madrid, España, 2015)

Federici S, Reencantar el mundo, El feminismo y la política de los comunes (Traficantes de Sueños, Madrid, 2020) $<$ https://www.traficantes.net/sites/default/files/pdfs/map60 Reenc antar interior web.pdf > última consulta: 15/02/2021.

Federici S, Revolución en punto 0, Trabajo Doméstico, Reproducción y Luchas Feministas (Traficantes de Sueños, Madrid, España, 2013) $<$ https://www.traficantes.net/sites/default/files/pdfs/map36 federic i.pdf> última consulta: 15/02/2021. 
Ferrajoli L, Manifiesto por la Igualdad (Editorial Trotta, Madrid, 2019)

Gilligan C, In a different voice: psychological theory and women's development (Harvard University Press, 1993)

Hart M y Negri A, Imperio (Paidós, Barcelona, España, 2005)

Hardy C, Hambre + Dignidad = Ollas Comunes (Segunda edición, LOM ediciones, agosto de 2020)

$<$ https://eurosocial.eu/wp-

content/uploads/2020/10/Hambredignidad web.pdf> última consulta: $15 / 02 / 2021$.

Harvey D, Breve historia del neoliberalismo (Akal, 2007)

Laval C, Dardot P, Común (Editorial Gedisa S.A, 2015)

Mies M y Shiva V, Ecofeminismo, teoría, crítica y perspectivas (Icaria, Barcelona, España, 2017)

Peter L, Stop the Thief! The Commons, Enclosures and Resistance, (Spectre, 2014)

Luxemburgo R, La acumulación del capital: Estudio sobre la interpretación económica del imperialismo (Cenit, Madrid, 1993)

Ostrom E, El gobierno de los bienes comunes (Primera edición, Fondo de Cultura Económica, México, Distrito Federal, 2000) Recuperado de: $<$ https://www.crim.unam.mx/web/sites/default/files/El\%20gobiern o\%20de\%20los\%20bienes\%20comunes.pdf> última consulta: $15 / 02 / 2021$.

Peces- Barba G, Curso de Derechos Fundamentales, Teoría General, (Universidad Carlos III de Madrid, Madrid, 1995)

Shiva, Vandana., Manifiesto para una democracia de la tierra, justicia, sostenibilidad y paz (Ediciones Paidós Ibérica, Barcelona, España, 2006)

\section{2.- Artículos}

Dalla Costa M, "La puerta del huerto y del jardín" (2005) Nóesis, Revista de Ciencias Sociales y Humanidades, pp. 79-101.

$<$ https://www.redalyc.org/articulo.oa?id=85915205> última consulta: 15/02/2021.

Díaz F, "Comunidad y Comunalidad" (2004) Diálogos en acción, segunda etapa, pp. 365-373.

$<$ http://rusredire.lautre.net/wp-content/uploads/Comunidad.-y0comunalidad.pdf > última consulta: 15/02/2021.

Grosfoguel R, "Del extractivismo económico al extractivismo epistémico y al extractivismo ontológico: una forma destructiva de conocer, ser y estar en el mundo" (Enero-Junio 2016) Tabula Rasa, Bogotá Colombia, No. 24, pp.123-143.

<https://revistas.usc.gal/index.php/ricd/article/view/3295> última consulta: 15/02/2021.

Gudynas E, "Teología de los extractivismos" (2016) Tabula Rasa, Bogotá Colombia, No.24, pp. 25-55. 
<https://www.revistatabularasa.org/numero24/> última consulta: $15 / 02 / 2021$.

Gudynas E, "Extracciones, extractivismos y extrahecciones, un marco conceptual sobre la apropiación de recursos naturales" (2013) Centro Latinoamericano de Ecología Social, Montevideo, Uruguay, No. 18.

$<$ https://www.researchgate.net/publication/281748932 Extraccione s Extractivismo y Extrahecciones Un marco conceptual sobre I

a apropiacion de recursos naturales $>$ última consulta: 15/02/2021.

Harvey D, "El nuevo imperialismo: Acumulación por desposesión" (2005) CLACSO, Buenos Aires, Argentina.

$<$ https://ticsymovimientos.files.wordpress.com/2017/03/harveyacumulacic3b3n-por-desposesic3b3n.pdf $>$ última consulta: $15 / 02 / 2021$.

Hardin G, "La tragedia de los comunes" (2004) CULCYT: Cultura Científica y Tecnológica, Vol.1, No 3, 2.

$<$ https://dialnet.unirioja.es/servlet/articulo?codigo $=7270922>$ última consulta: 15/02/2021.

Lloredo A, "Bienes comunes" (2020) Eunomía. Revista en Cultura de la Legalidad, 19, pp. 214-236.

<https://e-revistas.uc3m.es/index.php/EUNOM/article/view/5709>

última consulta: 15/02/2021.

Machado A, "Ecología Política de los Regímenes Extractivistas de reconfiguraciones imperiales y re existencias decoloniales en Nuestra América" (2015) Bajo el volcán, año 15, número 23, Puebla, México, pp. 11-

51.<https://www.redalyc.org/pdf/286/28643473002.pdf> última consulta: $15 / 02 / 2021$.

Morens $D$ y Fauci A, "Emerging Pandemic Diseases: How We Got to COVID-19" (2020) Cell Press

$<$ https://www.cell.com/action/showPdf?pii=S00928674\%2820\%2931012-6> última consulta: 15/02/2021.

Ribotta S, "Pobreza, Justicia y Hambre en América Latina y el Caribe. Debatiendo sobre la justicia mientras 53 millones de latinoamericanos sufren hambre" (2010) Revista Electrónica Iberoamericana, Vol.4 (1), pp.144-180.

$<$ https://www.urjc.es/images/ceib/revista electronica/vol 42010 1/REIB 0410 Silvina.pdf> última consulta: 15/02/2021.

Riechmann J, "El síntoma se llama calentamiento climático pero la enfermedad se llama capitalismo" (2014) web viento sur, pp.1-69, $<$ https://www.elviejotopo.com/wpcontent/uploads/2016/01/Texto Riechmann.pdf> última consulta: 15/02/2021. 
Rodríguez $\mathrm{P}$, "Reformular los derechos desde una visión relacional. El fin de la inmunidad y la autosuficiencia" (2017) Derechos y Libertades, número 36, Época II, pp. 135-166. $<$ https://e-archivo.uc3m.es/handle/10016/26205> última consulta: $15 / 02 / 2021$.

\section{3.- Informes}

CEDRSSA "La agricultura y su relación con la pobreza en México", (2020) CEDRSSA. <http://www.cedrssa.gob.mx/files/b/13/17Agricultura pobreza.pd $\underline{\mathrm{f}>}$

última consulta: 15/02/2021.

\section{4.- Web}

Hiner $\mathrm{H}$, "Las raíces históricas de las ollas comunes"(Observatorio de Género y Equidad)

$<$ http://oge.cl/las-raices-historicas-de-las-ollas-comunes/> última consulta: 15/02/2021. 